\title{
Fuelling Future Emissions - Examining Fossil Fuel Production Outlooks Used in Climate Models
}

\author{
Mikael Höök \\ Uppsala University \\ Sweden
}

\section{Introduction}

The anthropogenic component of projected climate change is dependent on the future emissions of greenhouse gasses. Energy production is, with a roughly $60 \%$ share, the principal contributor to mankind's release of $\mathrm{CO}_{2}$ to the atmosphere. This is predominantly caused by the use of fossil fuels in various combustion processes. Consequently, anthropogenic emissions and global warming are fundamentally linked to future energy production. Projections of how the global energy system will develop over the next century are cornerstones in the assessment of future climate change caused by mankind.

The climate models used by the Intergovernmental Panel on Climate Change (IPCC) and many others rely on various emission scenarios to depict possible trajectories for future fossil fuel production and their correlating release of $\mathrm{CO}_{2}$. The Special Report on Emission Scenarios (SRES) (the current set of emission scenarios) was published by the IPCC in 2000 and remains an integral part of climate change modelling. This chapter critically reviews the emission scenarios witnessed throughout history, their underlying assumptions on resource availability, production expectations, and compares them with other models and studies that have drawn up projections into the future. Future scenarios with high emissions of $\mathrm{CO}_{2}$ also display significant increases in world production of oil, natural gas and coal.

As of 2009, world oil production remains at 85 million barrels per day or 3800 million tons of oil equivalents (Mtoe) annually, with coal and natural gas 3400 Mtoe 2700 Mtoe per year respectively (BP, 2010). A tenfold increase in world gas production is foreseen in some scenarios, while others project future oil production to reach 300 million barrels per day by 2100. For example, 16 of the 40 coal scenarios contained in SRES simply grow exponentially until the year 2100. In addition, the emission scenarios also contain assumptions about future prices, technological developments and many other details related to fossil energy exploitation.

Can such assumptions be justified in the light of available fossil fuel resources and reasonable expectations on how fast such deposits can be exploited? Depletion of the world fossil energy resources, primarily oil, is a growing problem and is reflected in recent studies. This chapter also examines whether these results and observations have been incorporated in the emission scenarios used in climate models. 


\subsection{Historical background}

The Swedish Nobel prize laureate Svante Arrhenius (1896) was among the first to theorize about the impact of $\mathrm{CO} 2$ on the earth's climate. However, these early ideas were met with criticism and fell into obscurity until the 1950s. Growing concern about mankind's increasing impact on the environment and refined analytical methods revitalized the issue of greenhouse gases after the 1950s. Separate threads of research were pursued by isolated groups of scientists, although an increasing number of studies pointed towards a connection between global warming and anthropogenic emissions of greenhouse gases (Peterson et al., 2008). However, both mainstream media and politicians did not express concern over any of these findings until much later.

In the 1980s, the World Meteorological Organization (WMO) and the United Nations Environment Programme (UNEP) began to investigate the role of carbon dioxide and other emissions. Their interest leads to the establishment of the IPCC in 1988. This new organization was given the task of assessing the scientific, technical and socio-economic information relevant for understanding anthropogenic climate change. Their results have been published in several assessment reports and some special reports over the years (IPCC, 1990; 1995; 2001; 2007). However, the results are also dependent upon a number of underlying assumptions about future fossil fuel production and corresponding emissions.

Various future pathways for society, its energy system and the associated release of greenhouse gases are a cornerstone in the assessment of future climate change. Such outlooks are commonly referred to as emission scenarios and are being used as input in to climate models that transform the projected emissions into climatic changes. Throughout its existence the IPCC has used a number of such emission scenarios. The first set, published in 1990, was followed by subsequent sets published in 1992 and 2000. Titles, methods, classifications, assumptions have all changed over time and this has been reviewed by Girod et al. (2009).

The 1995 IPCC review of the old emission scenarios recommended that the full range of scenarios should be used as an input rather than just a single scenario. The conclusion was that there was no objective basis on which to assign likelihood to any of the scenarios (SRES, 2000). Meanwhile, a number of other weaknesses were also identified, such as the limited range of carbon intensities, the absence of a scenario with economic closure in the income gap between industrial and developing countries (SRES, 2000), or how the rapid growth in sulphur emissions did not reflect regional and local air quality concerns that might prompt limits on the future release of sulphur in to the atmosphere (Grübler, 1998).

All scenarios from 1992 where found to exaggerate one or more current climate and economic trends, leading to correspondingly exaggerated atmospheric greenhouse gas concentrations (Gray, 1998). In May 1996, the IPCC decided to develop new scenarios and initiated the painstaking process of developing a new set for use in future climate change assessments (Nakićenović et al., 1998). This resulted in the current emission scenario set often known as the Special Report on Emission Scenarios (SRES) - being published in 2000. This report is the basis for the majority of all recent long-term climate change projections, including those of the current Fourth Assessment Report (IPCC, 2007).

SRES (2000) presents 40 scenarios and calculates the greenhouse gas emissions associated with those scenarios. These scenarios are based on a literature review, the development of emmission narratives, and the quantification of these narratives with the help of six integrated models from different countries. The IPCC links $\mathrm{CO}_{2}$ emissions to four specific drivers, namely population; economic activity (gross domestic product or GDP) per capita; 
energy intensity (primary energy consumption per unit of GDP); and carbon intensity $\left(\mathrm{CO}_{2}\right.$ emissions per unit of energy) (Pielke et al. 2008). Consequently, SRES illustrates that the future emissions, even in the absence of explicit environmental policies, very much depend on the choices that people make, how economies and technologies are structured, the energy sources that are preferred and how people use available land area.

\subsection{Scenario probabilities in SRES}

Regarding the scenarios, IPCC state that "they represent pertinent, plausible, alternative futures" and derive from a descriptive and open-ended methodology that aims to explore alternative futures (SRES, 2000). The emission scenarios are claimed to be neither predictions nor forecasts, even though they are commonly used as such. Additionally, no probabilities or likelihoods are assigned to any of the scenarios. All scenarios are deemed equally plausible and valid as required by the Terms of Reference (SRES, 2000).

The emissions scenarios are used as an input to various climate models to depict how the climate may change under various forms of anthropogenic emissions. Some outcomes are more desirable than others, but the equal probability assumption can act as a potential obstacle. Planners and engineers, who need to make decisions based on the impacts of climate change, must have a grasp of the inherent uncertainties in the guiding projections as well as the probabilities of the different outcomes. Further discussion on these issues can be found in Walsh et al. (2004) or Green et al. (2009).

The absence of likelihoods in SRES triggered critique (Schneider, 2001; 2002; Webster et al., 2002) highlighting that policy analysts and decision-makers need probability estimates to assess the risks of climate change impacts resulting from these scenarios. The SRES team (Grübler and Nakicenovic, 2001) countered with the claim that social systems (important in emission scenarios) are fundamentally different from natural science systems and are largely dependent on the choices people make.

Equally valid scenarios cannot be realistic, since the range is due to a combination of component ranges of uncertainty, and thus the extremes of this range must be less probable than the central estimate (Jones, 2001). The equal probability of each emission scenario is a rather peculiar assumption and has been seen as an attempt to assign unjustifiably high weight to more extreme visions compared to reasonable outlooks (Höök et al., 2010a; Patzek and Croft, 2010). Clearly, the handling of uncertainty and the appropriateness of assigning subjective probabilities to scenarios is a matter of lively debate and an important, unresolved challenge in the application of climate scenarios (Dessai et al., 2007; Groves and Lempert, 2007; Schenk and Lensink, 2007; van Vuuren et al., 2008; Lemos and Rood, 2010).

\subsection{The role of fossil fuels in the world's energy system}

Throughout the industrial revolution, energy derived from fossil fuel has been the driving force behind the industrialized world and the economic growth. Energy output from fossil fuel has grown from insignificant levels in 1800 to an annual output of nearly 10000 million tons of oil equivalents (Fig. 1). At present, over $81 \%$ of the total primary energy in the world is produced from fossil fuels with oil accounting for $33.2 \%$, coal for $27.0 \%$ and natural gas for $21.1 \%$ (IEA, 2010). Combustible renewable and waste $(10.0 \%)$, Nuclear power $(5.8 \%)$ and hydroelectric dams (2.2\%) are the largest contributors to the global energy system after fossil energy, but they account for only a smaller share of the world's primary energy supply (IEA, 2010). Only $0.7 \%$ of the world's primary energy is derived from geothermal, wind, solar or 
other alternative energy sources. More specifically, wind power accounted for only $0.2 \%$ of the global primary energy supply with its 340 TWh contribution in 2009 (World Wind Energy Association, 2010).

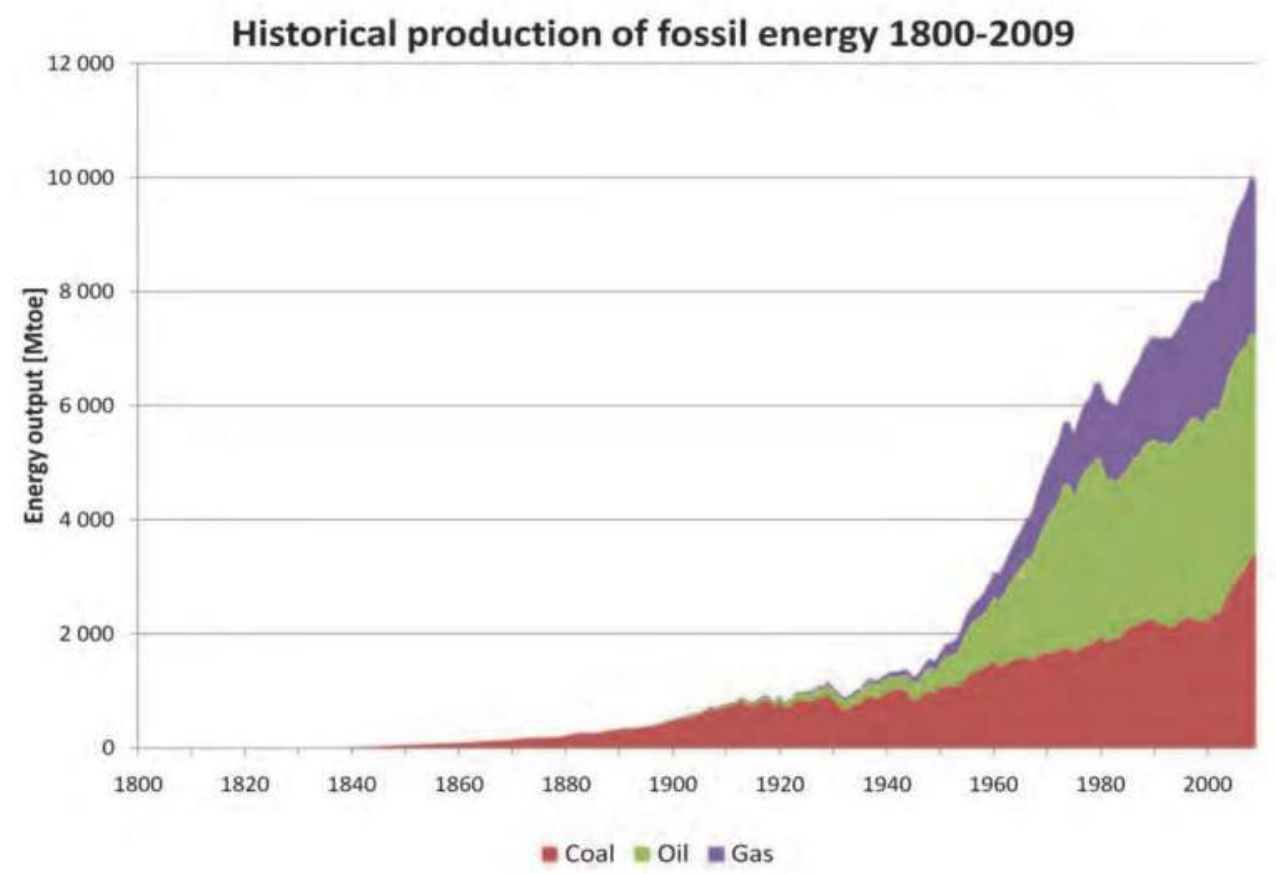

Fig. 1. Production of fossil energy in the world from 1800 to 2009. Based on the author's own compilation of historical data.

\subsection{Importance of future energy systems for future emissions}

For the foreseeable future, fossil energy will remain the backbone of the world's energy system, given their present dominance. Furthermore, the worlds reliance on fossil energy brings about an associated problem, namely the emissions connected to the combustion of these fossil fuels. In fact, energy production is also the dominating source of anthropogenic greenhouse gasses (GHG), particularly carbon dioxide. In 2008, nearly 30 billion tons of $\mathrm{CO}_{2}$ were emitted due to fossil fuel consumption (IEA, 2010). Around 57\% of all global anthropogenic GHGs derive from fossil fuel combustion, with energy supply as the largest contributing sector (Fig. 2). Anthropogenic global warming and climate change caused by GHG emissions exhibits a strong and fundamental link to fossil energy production and shapes how it will develop over the coming decades. Consequently, examining likely and possible trajectories of the future energy use and production are vital for understanding future climate change based on GHG emissions from human activities.

Lior (2009) reviewed current energy use and possible paths to the future, but without venturing into specific details surrounding upcoming challenges. On the other hand, such visions have been made by many others and there is a growing body of evidence 
indicating that there will be challenges with supplying enough fossil energy for continued business-as-usual growth. Energy insecurity, i.e. the welfare impact of either physical unavailability of energy or prices that are not competitive or are overly volatile, has often been identified as a major challenge for the world in the 21st century together with anthropogenic climate change (Curtis, 2007; McCartney et al., 2008; Moriatry and Honnery, 2009). How are these two problems interconnected? Can both these challenges haunt mankind at the same time?

Despite awareness of fossil fuel exhaustion and the common knowledge about the finite supply of oil, gas and coal, physical resource availability has not been widely addressed in the long-term outlooks used to assess the risk of anthropogenic climate change. Contrary to common sense, energy is usually treated as a limitless exogenous input to economic planning with the result that energy demand is well defined, but disconnected from the physical and logistical realities of supply (Nel and Cooper, 2009). In essence, SRES (2000) features a set of scenarios not compatible with the possibility that the implied recoverable volumes and extraction rates of fossil fuels are physically impossible. Despite the obvious relevance of peak oil to future anthropogenic emissions it has received little attention in the climate change debate (Kharecha and Hansen, 2008; Crúcz et al., 2010). In many ways, extreme climate change projections are commonly built on the assumption that there will be essentially no issue at all with future supply of fossil energy.

\section{Shares of global anthropogenic GHG emissions}

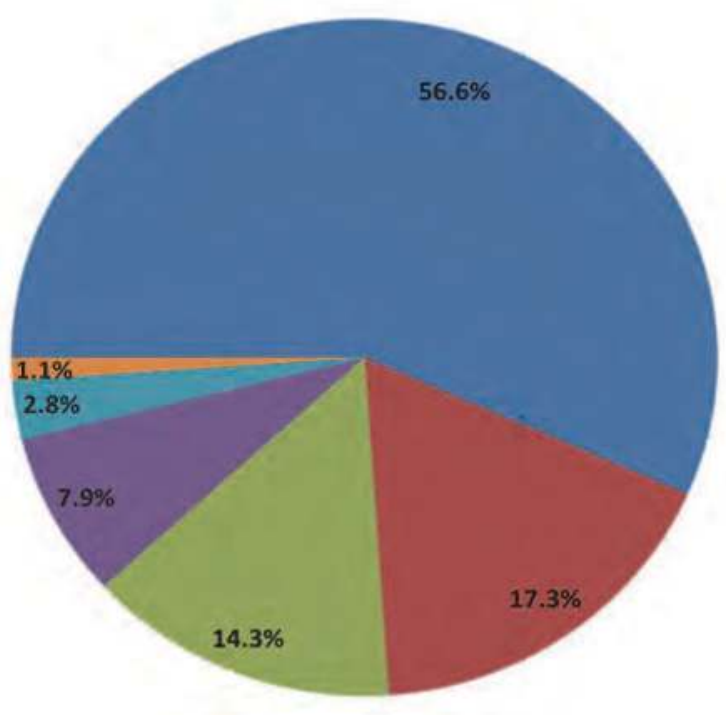

a $\mathrm{CO} 2$ from fossil fuel use

- $\mathrm{CO} 2$ from deforestation, decay and peat

$\mathrm{CH} 4$ from agriculture, waste and energy

N2O from agriculture and others

aO2 from other sources

Fluorine-gases

Fig. 2. Shares of global anthropogenic greenhouse gas emissions by origin (IPCC, 2007). 


\section{A closer look at the emission scenarios}

SRES is built around 40 different scenarios for future development of the society, its energy system and emissions. The writing teams formulated the narratives in a process that identified driving forces, key uncertainties, possible scenario families and their logic. Each of the four scenario families is described by a specific storyline to simplify the procedure of depicting alternative future developments. Within each scenario family different variations of global and regional development and their implications for global greenhouse gas emission were explored.

Six different modelling teams (Table 1) used state-of-the-art computer models and experience considering long-range development of economic, technological and environmental systems to generate quantifications of the narratives, which laid the foundation for the different scenarios. SRES storyline titles have been kept simple and are named A1, A2, B1 and B2. They can be straightforwardly shown in a two-dimensional tree, depicting the global-regional focus and the economic-environmental orientation (Fig. 3).

It is important to notice that there is no business-as-usual scenario, even though the A1 family is often used as an example of how continued focus on economic growth in a Western way might evolve globally. In addition, disaster scenarios were also omitted and it was also decided that possible surprises, such as a new world war or major depression, should not be considered. This has been described as a built-in linear logic and utopian thought (Hjerpe and Linnér, 2008). It is also important to highlight that none of the scenarios include additional climate initiatives such as policies to limit GHG gases or to adapt to the expected climate change.

\begin{tabular}{|c|c|c|}
\hline Abbrevation & Full Name & Origin \\
\hline AIM & Asian Pacific Integrated Model & $\begin{array}{l}\text { National Institute of Environmental } \\
\text { Studies (NIES), Japan }\end{array}$ \\
\hline ASF & $\begin{array}{l}\text { Atmospheric Stabilization } \\
\text { Framework Model }\end{array}$ & ICF Consulting, USA \\
\hline IMAGE & $\begin{array}{l}\text { Integrated Model to Assess the } \\
\text { Greenhouse Effect }\end{array}$ & $\begin{array}{l}\text { National Institute for Public Health } \\
\text { and Hygiene (RIVM), Netherlands }\end{array}$ \\
\hline MARIA & $\begin{array}{l}\text { Multiregional Approach for } \\
\text { Resource and Industry } \\
\text { Allocation }\end{array}$ & Science University of Tokyo, Japan \\
\hline MESSAGE & $\begin{array}{l}\text { Model of Energy Supply } \\
\text { Strategy Alternatives and their } \\
\text { General Environmental Impact }\end{array}$ & $\begin{array}{l}\text { International Institute of Applied } \\
\text { Systems Analysis (IIASA), Austria }\end{array}$ \\
\hline MINICAM & $\begin{array}{l}\text { The Mini Climate Assessment } \\
\text { Model }\end{array}$ & $\begin{array}{l}\text { Pacific Northwest National } \\
\text { Laboratory (PNNL), USA }\end{array}$ \\
\hline
\end{tabular}

Table 1. Model names in SRES and developing team behind them.

The four main narratives and their corresponding scenario families describe future societies that are significantly wealthier than the current world. There has been a significant discussion around the use of Market Exchange Rates (MER) or Purchasing Power Parity (PPP) and the economic differences it leads to in the long time scales used. For example, McKibbin et al. (2007) show that MER terms can lead to more than $40 \%$ higher emission 
projections compared to estimates based on PPP. This has been discussed by Castles and Henderson (2003), Tol (2006), and van Vuuren and O'Neill (2006).

Closer discussions on the actual models and the concepts they rely on have been done by van Ruijven et al. (2008). The energy ladder, i.e. a simplified substitution-based concept, as well as the environmental Kuznetz curve, i.e. a U-shaped relation between economic development and environmental impact, are generally consistently used in SRES. However, van Ruijven et al. (2008) stress that the models might need to be reformulated to better capture the dynamics of real world development, since SRES only depicts the world in four large regions and uses a limited amount of socio-economic and energy data. Further analysis of assumptions regarding demographics, economics and social development is beyond the scope of this chapter.

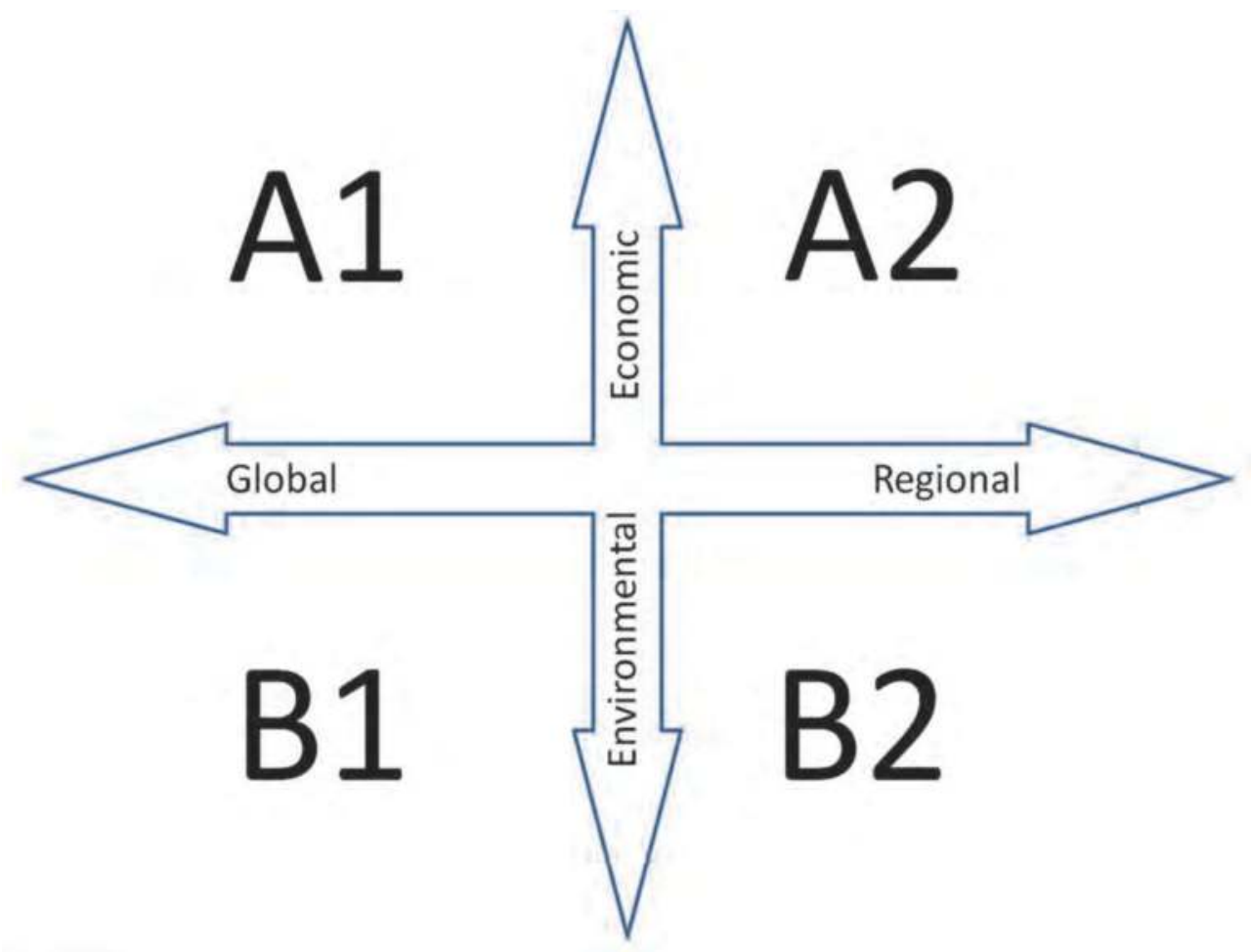

Fig. 3. Schematic illustration of the SRES scenarios. The four scenario families are shown, very simplistically, as branches of a two-dimensional matrix. Each scenario is based on a common specification of the main driving forces such as population, economy, technology, energy, land-use and agriculture. Adapted from SRES (2000).

\subsection{The four scenario families}

All the qualitative and quantitative features of scenarios belonging to the same family were set to match the corresponding features of the underlying storyline. Together, 26 scenarios were harmonised to have the same common assumptions about global population and gross 
domestic product (GDP) growth (SRES, 2000; Siversson, 2004). Although the scenarios share a few basic assumptions, they can differ substantially in other aspects, such as availability of fossil-fuel resources, the rate of energy-efficiency improvements, the extent of renewable energy development, and the consequential GHG emissions.

The remaining 14 scenarios are alternative interpretations of the four scenario narratives with different rates of economic growth and variations in population projections. These variations reflect the modelling teams' choice as an option to the harmonised scenarios. Another form of scenario is the marker scenario, which is considered by the SRES writing team to be the most illustrative scenario of a particular storyline, but marker scenarios should not be regarded as more likely than any other scenario either. More detailed descriptions on the scenario families and their characteristic parameters can be found in SRES (2000), even though the main qualities of each storyline can be found in table 2 and are briefly presented below.

\begin{tabular}{|c|c|c|c|c|c|c|c|}
\hline Family & A1 & & & & A2 & B1 & $\overline{B 2}$ \\
\hline Subgroup & A1C & A1G & A1 & A1T & A2 & B1 & B2 \\
\hline $\begin{array}{l}\text { Population } \\
\text { growth }\end{array}$ & Low & Low & Low & Low & High & Low & Medium \\
\hline GDP growth & $\begin{array}{l}\text { Very } \\
\text { high }\end{array}$ & $\begin{array}{l}\text { Very } \\
\text { high }\end{array}$ & $\begin{array}{l}\text { Very } \\
\text { high }\end{array}$ & $\begin{array}{l}\text { Very } \\
\text { high }\end{array}$ & Medium & High & Medium \\
\hline Energy use & $\begin{array}{l}\text { Very } \\
\text { high }\end{array}$ & $\begin{array}{l}\text { Very } \\
\text { high }\end{array}$ & $\begin{array}{l}\text { Very } \\
\text { high }\end{array}$ & High & High & Low & Medium \\
\hline $\begin{array}{l}\text { Land-use } \\
\text { changes }\end{array}$ & $\begin{array}{l}\text { Low- } \\
\text { medium }\end{array}$ & \begin{tabular}{|l|} 
Low- \\
medium
\end{tabular} & Low & Low & $\begin{array}{l}\text { Medium- } \\
\text { high }\end{array}$ & High & Medium \\
\hline $\begin{array}{l}\text { Resource } \\
\text { availability }\end{array}$ & High & High & Medium & Medium & Low & Low & Medium \\
\hline $\begin{array}{l}\text { Technological } \\
\text { development }\end{array}$ & Rapid & Rapid & Rapid & Rapid & Slow & Medium & Medium \\
\hline $\begin{array}{l}\text { Change } \\
\text { favouring }\end{array}$ & Coal & $\begin{array}{l}\text { Oil \& } \\
\text { Gas }\end{array}$ & Balanced & $\begin{array}{l}\text { Non- } \\
\text { fossils }\end{array}$ & Regional & Efficiency & $\begin{array}{l}\text { "Dynamics } \\
\text { as usual" }\end{array}$ \\
\hline
\end{tabular}

Table 2. Main characteristics of development in different scenario families and groups, as applied to harmonized scenarios. Adapted from SRES (2000)

The A1 storyline and corresponding scenario family is by far the largest of the four scenario families in SRES (2000). This family is characterized by visions of a future world with very rapid economic development, low population growth and swift implementation of new and more efficient technologies. The key plots are convergence among regions, capacity building, and increased cultural and social interactions with a significant reduction in the difference in per capita income. The A1 family is the largest and branches out in several subfamilies, each exploring an alternative future with other preferences. One subfamily, A1C, focuses on coal and its development potential while A1G uses natural gas as the main energy source. A1T explores non-fossil energy sources, while the A1 subgroup uses a balanced energy mix.

The A2 family describes a very heterogeneous world. Here, the main concept is self-reliance and preservation of local identities and cultures. Global fertility patterns converge very slowly which results in high population growth. Economic development is primarily 
focused on regional growth and per capita economic growth and technology change is more fragmented and slower than in other scenario families.

The B1 scenario family depicts a world with the same low population as the A1 storyline, but with rapid changes in economic structures. The gap between developed and developing countries diminishes as the world economy moves toward a service and information economy. This results in reductions in material intensity, and the implementation of clean and resource-efficient technologies. The key concept here is on global solutions to economic, social and environmental sustainability, including improved equity, but without additional climate initiatives.

The B2 scenario family is similar to the B1 family, but the emphasis is put on local solutions to economic, social and environmental sustainability. It results in a world with moderate population growth, intermediate economic growth and less but more diverse technological change than in the B1 and A1 storylines. B2 is oriented toward environmental protection and social equity, but also focuses on local and regional initiatives.

\section{Resource availability in SRES}

Fossil fuel use is the dominating source behind GHG emissions and so the assumed availability and future production paths are vital for projecting atmospheric concentration of $\mathrm{CO} 2$ and anthropogenic climate change. However, the underlying assumptions and data sources in SRES (2000) are old and even outdated due to new knowledge and changing conditions in the world. This has chiefly to do with the one-sided view on fossil fuel availability expressed by the works that SRES relies on, chiefly relying on economic models rather than geological and technical estimates (Höök et al., 2010a).

The works of Rogner (1997) and Gregory and Rogner (1998) are the major sources for the detailed discussion of available fossil fuel amounts in SRES (2000). Rogner (1997) states that additional occurrences beyond the common resource base, i.e. unconventional hydrocarbons such as tar sands and gas hydrates, makes fossil fuels appear as an almost unlimited energy source, provided that economic and technological development are favourable. Rogner (1997), and thereby SRES (2000), conveys the notion that "the sheer size of the fossil resource base makes fossil sources an energy supply option for many centuries to come." More specifically, the low long-term costs are worth mentioning, as the fossil energy cost is assumed to be not significantly higher than the market price of the 1990s (i.e. crude spot prices of around 17 dollars/barrel).

To arrive at these conclusions, Rogner (1997) compiled a number of hydrocarbon resource estimates prior to 1997, originating from sources such BP, World Energy Council, German Federal Institute of Geosciences as well as academic studies. For conventional petroleum, Rogner (1997) states an ultimate recoverable resource base of 2800 Gigabarrels (Gb) and the aggregated number for unconventional oil occurrence is $16500 \mathrm{~Gb}$, where unconventional includes heavy oil, tar sands and oil shale. Unconventional oil is expected to become the main source in the long run, given its presence in vast quantities. Comparison between Rogner (1997) and recent estimates of available unconventional oil can be found in Greene et al. (2006).

Rogner (1997) presents a similar picture for natural gas, with only 2900 gigabarrels of oil equivalents (Gboe) of conventional gas ( 3100 Gboe if natural gas liquids are included) and 142000 Gboe of unconventional quantities. Over 95\% of unconventional gas is assumed to be methane hydrates (primarily residing on sea floors), while coal-bed methane, fractured 
shale, tight formation and remaining in-situ only constitute minor amounts. As a result, future gas availability must be tightly connected to methane hydrates and their development. Worldwide estimates of gas hydrates have decreased by many orders of magnitude (from $10^{18} \mathrm{~m}^{3}$ in $1970 \mathrm{~s}$ to $10^{15} \mathrm{~m}^{3}$ in 2000s) due to growing geological knowledge (Milkov, 2004), so much of the material used by Rogner (1997) is now outdated. The apparent importance of gas hydrates and the major expectation that is put on them in SRES (2000) appears debatable and should be highlighted for more discussion. The huge global estimates of hydrate methane are suspicious at best, and have nothing to do with the likelihood that hydrates will provide energy supply assurance for the future. An excellent review on facts and myths surrounding gas hydrates and their future as an energy source have been made by Beauchamp (2004).

For coal, Rogner (1997) highlights the many fluctuations in world reserve and resource assessments. The overview is very brief in comparison with oil and gas, mostly utilising the German Federal Institute of Geosciences (BGR) as the main source. The total coal resource is placed at 45800 Gboe, which would equal $8744 \mathrm{Gt}$ of coal (assuming $30 \mathrm{GJ} /$ ton coal). Nearly $60 \%$ of all coal is found in the most uncertain category. A complete summary of how world coal reserves and resources have evolved over time can be found in Höök et al. (2010b).

Gregory and Rogner (1998) rely largely on the resource estimates derived by Rogner (1997) but make a few new additions with resource estimates for renewable and non-fossil fuels. A significant share of the article is devoted to speculation and envisioning the feasibility of future conversion technologies, ranging from fuel cells and hydrogen to unconventional hydrocarbons such as oil shale or gas hydrates. Interestingly enough, Gregory and Rogner (1998) also mentions the "pessimistic" view on ultimate recoverable resources, represented by geologists and natural scientists in contrast to the "optimistic" view, lead by economists such as Adelman and Lynch. The notion of limits to future oil supply is quickly dismissed by Gregory and Rogner (1997) with grand expectations from new technology as well as economic arguments pointing towards the enormous amount of hydrocarbon molecules available in the Earth's crust. In essence, IPCC ad SRES has chosen to disregard the issues of resource depletion and the concept of geological, physical and technical limits based on little more than economic demand-driven models (Höök et al., 2010a, Valero and Valero, 2011).

\subsection{Resource depletion}

The term finite resource is frequently used but few people seem to ponder what it actually means. When it comes to natural resources, it can be argued that production limits are determined by the extraction and creation rates. If extraction of a resource is faster than replenishment rate the resource will be finite in the sense that it will eventually be exhausted (Höök et al., 2010c). All fossil fuels are finite and non-renewable natural resources, i.e. their deposits are limited either physically or economically. This comes from the simple fact that it takes millions of years for fossil fuels to form and they are rapidly extracted, making it impossible for the rate of creation to keep up with the rate of extraction. The issue of depletion and overexploitation of the natural resource base are not recent concerns. In fact, discussion has been taking place for quite some time, hailing back to the $18^{\text {th }}$ century where Malthus (1798) discussed the impact of growing exploitation of natural resources in an environment with limited capacity to sustain an ever increasing populace.

Similar reasoning was later expressed by Verhulst (1838) who found that any population subject to growth would ultimately reach a saturation level (usually described as the carrying capacity) and this environmental characteristic forms a numerical upper bound on 
the growth process. Later on, William Stanley Jevons (1856) foresaw limits to the growth of British coal production as a consequence of limited availability of workable coal.

In the 1950s, Hubbert (1956) was among the first to propose a modern framework for extrapolation of production curves of finite resources, primarily focused on oil. He also accurately predicted the peak of US oil production in 1970s.

More generally, possible limits to growth and how it would affect society were explored through system dynamics by the Club of Rome in their infamous report "The Limits to Growth" (Meadows et al. 1972). In hindsight, 30 years of reality actually concurs well with the "standard run" scenario (Turner, 2008). Sustained false statements, by mainly economists, discredited the report and made its call for fundamental policy changes and sustainability pass by relatively unnoticed (Turner, 2008). As life after the oil crisis of the 1970s returned to normal many of the issues raised concerning resource depletion were forgotten.

In late 1990s, two former oil company geologists, Colin Campbell and Jean Laherrere, examined reported reserves and extrapolated discovery curves (Campbell and Laherrere, 1998). Their conclusion was that the world is facing the end of cheap and abundant oil and that the maximum rate of oil production would occur somewhere around 2010. Many other studies performed since have arrive at similar dates (Bentley and Boyle, 2007).

Aleklett and Campbell (2003) addressed more issues and created an updated model for oil depletion along with a first expansion of the analysis to cover natural gas. Once again, doomsday accusations and claims of undue pessimism were targeted at these forecasts, mostly from economists. In retrospect, empirical observations show that nearly 60 countries have already passed their maximum production levels of oil (Sorrell et al., 2010). A most comprehensive summary of over 500 peer-reviewed studies on oil concluded that a global peak before 2030 appears likely and there is a significant risk of peaking before 2020 (UKERC, 2009). Sorrell et al. (2010) also found that forecasts that delay the peak of conventional oil production until after 2030 rest upon several assumptions that are at best optimistic and at worst implausible.

Clearly, the risks associated with future oil supply and how it can impacts the global energy system should be given serious consideration but none of this has been highlighted by the IPCC that continues to rely on the outdated material in SRES.

\subsection{Production projections made in SRES}

Total primary energy production from fossil fuels in the SRES outlooks range from around an increase of a mere 50\% from the 2009 level in the B1 family to over $400 \%$ in the A1 family (Fig. 4-7). There is a significant spread within the families, in particular among the scenarios belonging to the A1 family. The A1T-scenarios largely replaces fossil fuels with nuclear or renewable and remain at levels around present fossil energy contribution until 2100. Other subgroups depict significant increases of oil, gas and/or coal.

Not a single one of all 40 scenarios in SRES (2000) is projecting a future society with remarkably less fossil fuel dependence than at present. Closer studies, with projections broken up into oil, gas and coal, have been made by Höök et al. (2010a). The spread can also be significant. For example, A1G AIM reaches over 300 million barrels per day of oil production by 2100, while A1 ASF has phased out oil use entirely. Strangely enough, both of these outlooks are deemed equally probable. More than a tenfold increase in world gas and coal production is also projected. These outlooks are in stark contrast to the growing body of evidence that indicate that such high production pathways are unreasonable. 


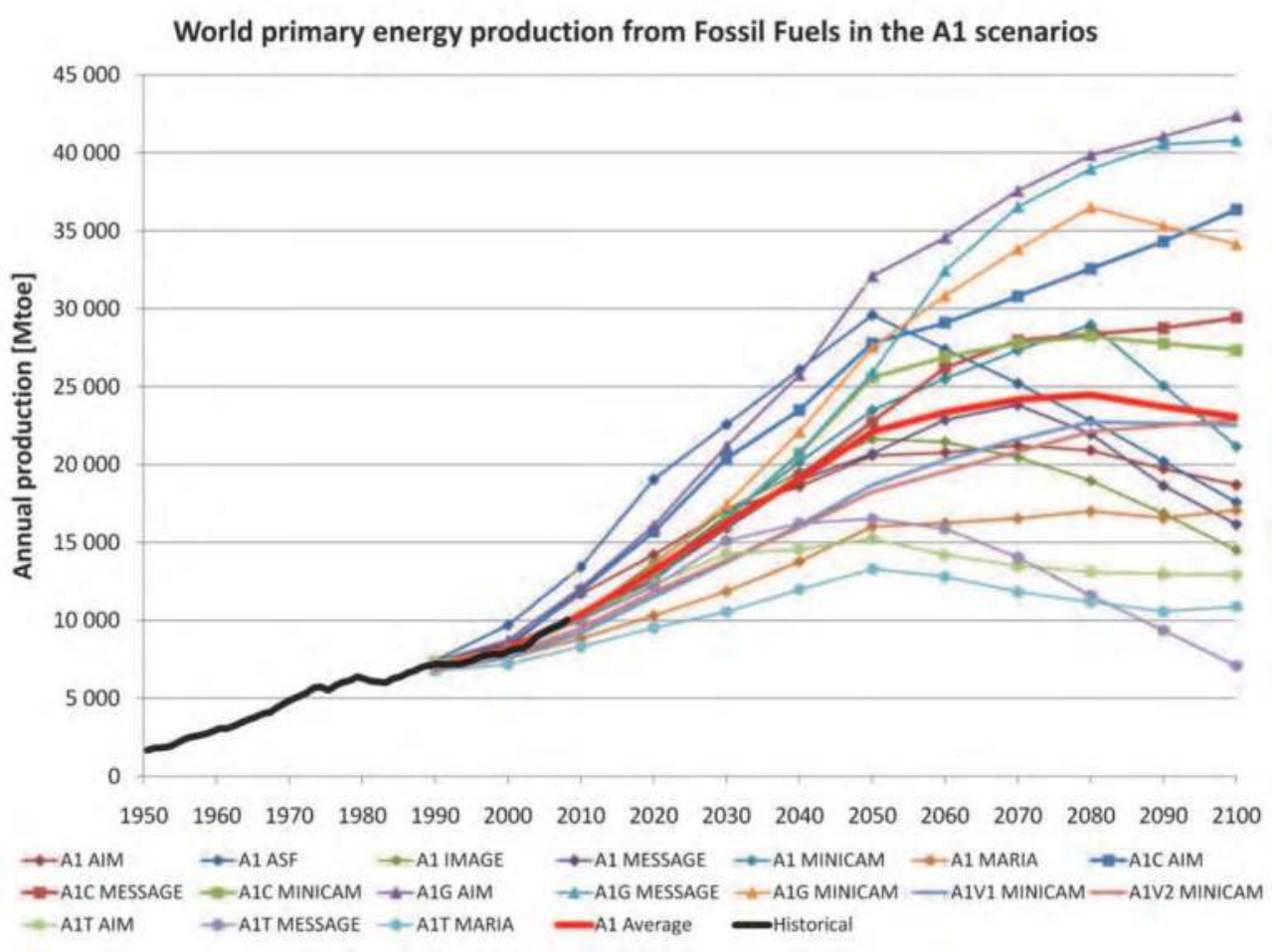

Fig. 4. World primary energy production from fossil fuels in the A1 family.

For coal, Patzek and Croft (2010) examined SRES and found that 2 scenarios peak in the year 1990, 3 in 2020, 3 in 2030, 3 in 2040, 13 in 2050, while in the 16 remaining scenarios coal production simply grows exponentially until the year 2100 . What happens after 2100 is not discussed in SRES (2000) and several scenarios simply end with high production levels. By 2100 most of the ultimate reserves of conventional oil, gas and coal discussed in most SRES scenarios will have been depleted (Höök et al, 2010a).

Rogner (1997) and SRES (2000) go to great lengths to point out that there are enough fossil resources, i.e. hydrocarbon molecules in the crust, to theoretically sustain production for a long time. However, the main message of Rogner (1997) shows a misunderstanding of the actual problem as well as avoidance of the question at stake, namely future production. Resources are irrelevant for production, unless they cannot be transformed to reserves and commercially exploited. Vast resources have little to do with the likelihood of significant future exploitation, as this is dependent on more factors than just geological availability.

Society is dependent on fossil fuel flows and future production is about the size of those flows. The size of the tank, i.e. the resource base, is of secondary importance as it is the tap that governs the flow rate and future utilization of fossil fuels in the society. Vast amounts of unconventional hydrocarbons are useless for preventing the coming of a production peak if they cannot be developed fast enough to offset the peaking of conventional flows.

There are also a few important observations that can be made from the arithmetic of growth. Every time a growing production doubles it takes more than all that has been used in all the 
preceding growth (Bartlett, 1993; 1999; 2004). Taking the average fossil energy production of A1 as an example (Fig. 4), it is projected that the global production of fossil energy in 2040 will be approximately twice as much as in 2010. In other words, it is stated that during these 30 years the world will produce and consume more fossil energy than the total that has been consumed since the dawn of the industrialized age. This is actually quite mind-bending when stated in this way in contrast to the exponential growth rates of a few percent more commonly seen. The amount of miners, equipment, permits, investments, regional issues and social acceptance needed to achieve this huge task is not discussed in SRES in any detail as everything is just aggregated into four large world regions.

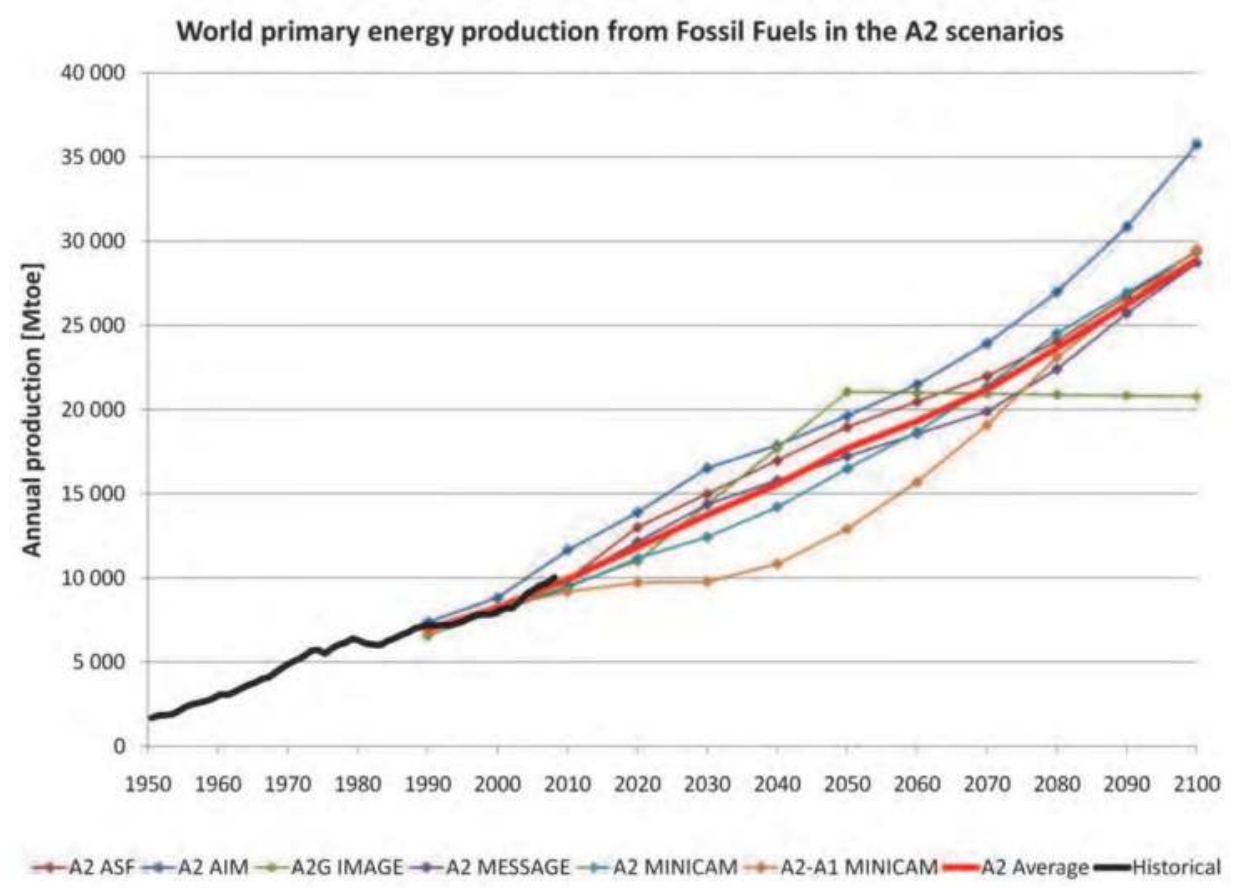

Fig. 5. World primary energy production from fossil fuels in the A2 family.

\subsection{Critical views on SRES}

Since SRES was published in 2000, there have been a number of critical concerns raised over the fossil fuel production outlooks contained in the emission scenarios. However, this debate did not become especially widespread. The public debate seemed to focus on the outcome of the climate models rather than the underlying assumptions.

One of the first to notice the optimistic production paths were Laherrere $(2001 ; 2002)$. He compared the IPCC emission scenarios with technical data and found them overly optimistic on future oil and gas supply, both regarding conventional and unconventional oil. By 2100, the A1G scenarios consume around 14 times more natural gas than in 2000 and Laherrere (2001) described this as "pure fantasy". He concluded that the IPCC assumptions about abundant volumes of cheap oil and gas were in dire need of revision. 


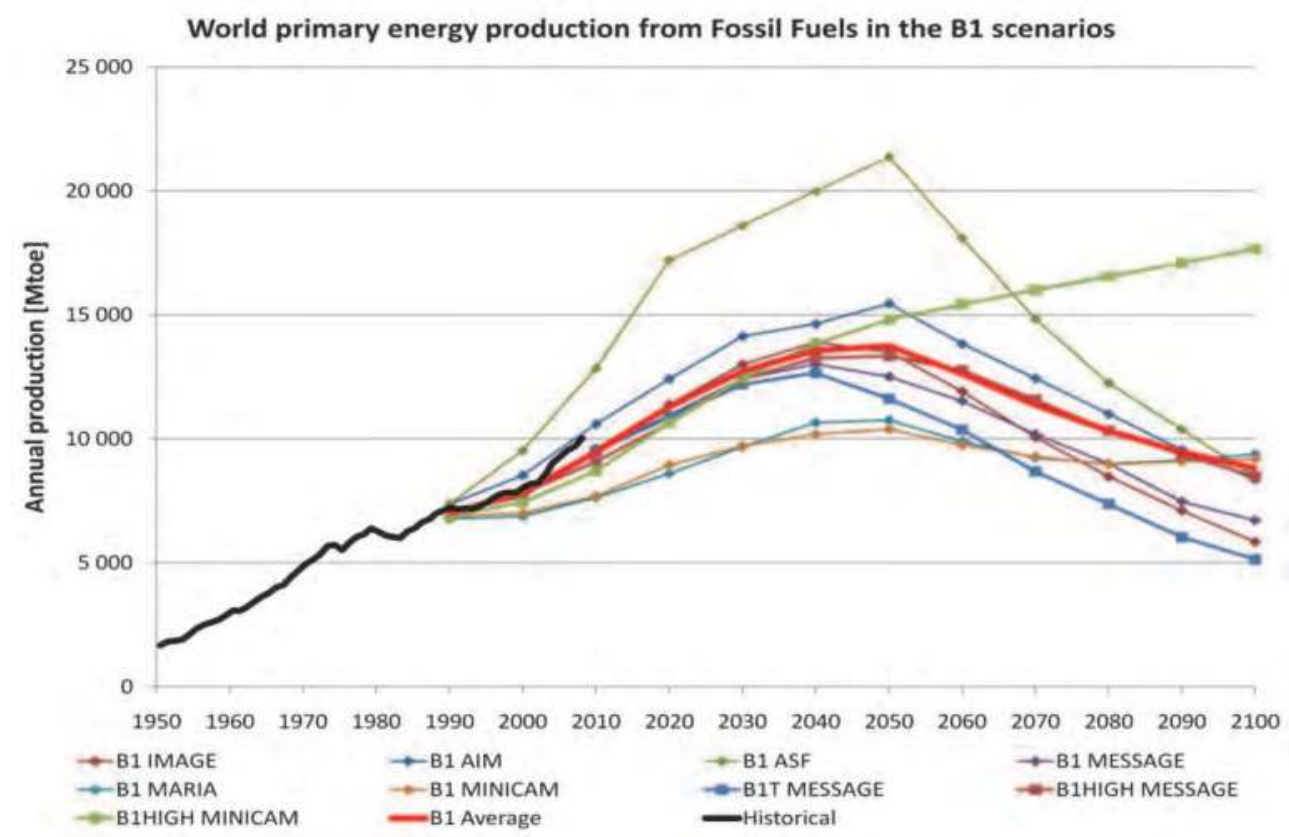

Fig. 6. World primary energy production from fossil fuels in the B1 family.

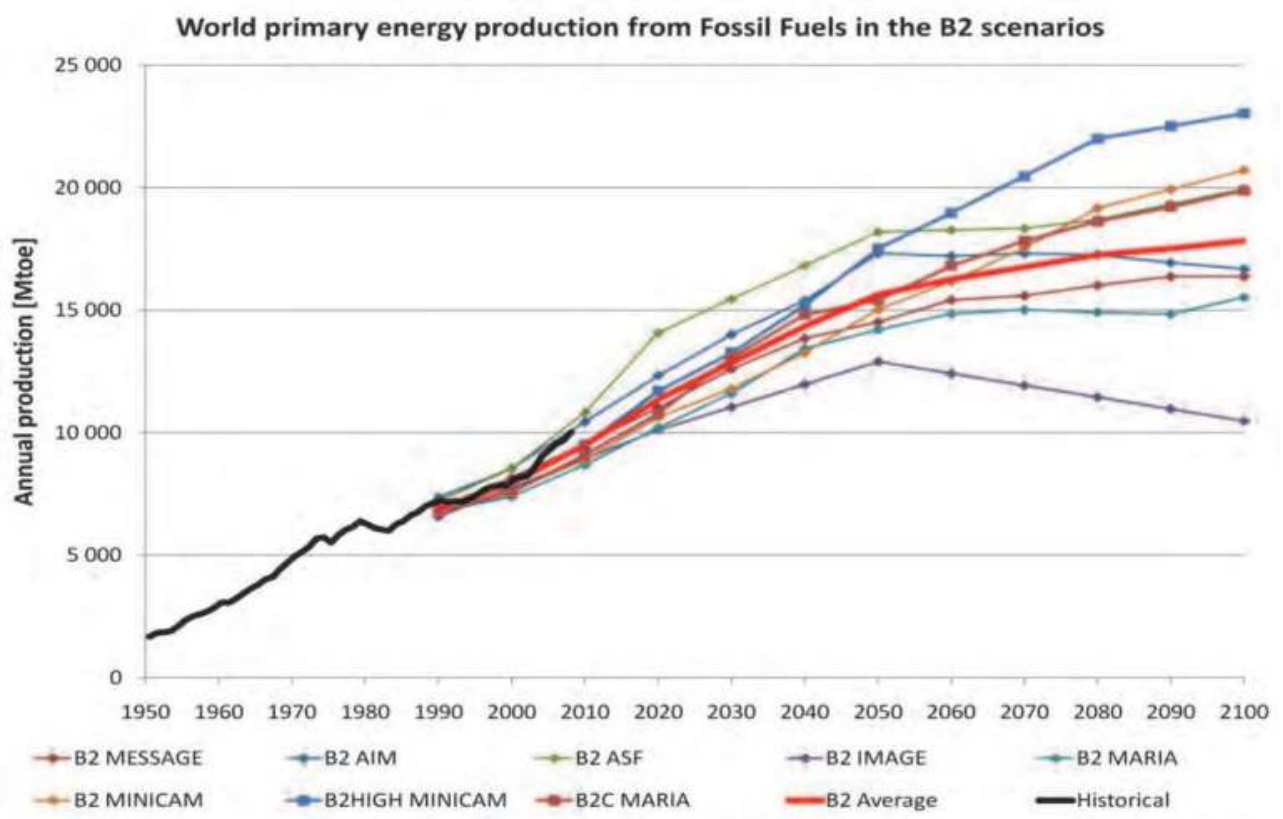

Fig. 7. World primary energy production from fossil fuels in the B2 family. 
Similar ideas were expressed by Campbell and Aleklett (Coghlan, 2003), who earlier had questioned the longevity of the world's oil and gas endowment (Aleklett and Campbell, 2003). Sivertsson (2004) was later showing major anomalies between all the 40 emission scenarios and expected future production and discoveries of gas and oil, using an updated methodology and improved data. The authors of SRES responded to this by claiming that the findings were too "conservative" and claimed that there was still plenty of coal to exploit. Rutledge (2007) expanded this analysis by including coal and came to the conclusion that the cumulative energy production and CO2 emissions from coal, oil and gas would be less than any of the IPCC emission scenarios. Different studies on future coal production levels all indicated that historical trends and reasonable production profiles were lower than depicted in SRES (Energywatch Group, 2007; Mohr and Evans, 2009; Höök et al., 2010b; Patzek and Croft, 2010). It was also shown that IPCC had been performing dubious summation of coal resources from the World Energy Council (WEC), despite the fact that WEC gave compelling reasons for not summing that category (Rutledge, 2011).

\subsubsection{Rates of change in SRES}

SRES (2000) presents a significantly important role for unconventional fossil hydrocarbon sources, justified by the works of Rogner (1997) and Gregory and Rogner (1998). For example, the B1 family assumes that the availability of huge unconventional oil and gas supplies, with a geographic distribution widely different from conventional resources, will have a significant impact on fuel supply and trade flows in the long term. Essentially, the depletion of conventional fossil fuels is expected to be smoothly offset as new technology allows exploitation of unconventional resources such as tar sands, gas hydrates and similar in the emission scenarios used by the IPCC. Another inadequacy is the lack of discussion about the details of the supply of fossil energy.

For oil, the world has a significant dependence on roughly 300 giant oil fields, which account for $60 \%$ of world oil production (Höök et al., 2009). The decline in existing production has been determined to be around $6 \%$ and this is a commonly accepted figure derived by several analysts, both from "optimistic" and "pessimistic" standpoints regarding future oil production (Höök et al., 2009 and references therein). This is equal to a required new annual production addition of $3-7 \mathrm{Mb} / \mathrm{d}$ and this puts some real numbers on what is required just to offset a decrease in existing production. This lack of detailed discussion on future production in SRES is questionable, because details such as those surrounding the giant fields have significant impact on actual production. The aggregated models and generalized assumptions appear questionable and should be clarified and reinforced to be considered realistic. At this point, IPCC and SRES (2000) seem far more optimistic regarding future oil production than the industry itself.

The attenuation of the peak oil decline requires more than $10 \%$ of sustained growth of nonconventional oil production over at least the next two decades (de Castro et al., 2009). Such sustained growth rates have not been seen for any of the global energy systems in history and are not expected by either of the dominating forecasting agencies, i.e. the IEA or the EIA. Even the BGR (2008), the main data source of Rogner (1997), states that: "after peak oil, the nonconventional oil production will rather modify the decline in oil supply than close the gap between demand and supply." More specifically, there appears to be more or less of a consensus about a global peaking of oil production before 2030 (UKERC, 2009). Alas, the foundation of future oil supply used by SRES (2000) is outdated and does not reflect the growing knowledge of the last decade. 
Similar optimistic assumptions have also been placed on gas and coal production within SRES (2000). To achieve ten-fold increases in global gas and coal production, an olympian amount of investment must be made but this appears unlikely from available long-term policies and planning documents. For gas, methane hydrates are identified as the important long-term supplier in SRES (2000). In reality, exploitation of gas hydrates is still far from commercially feasible. Beauchamp (2004) points out that, by any standard, gas hydrates will not come cheap - economically, energetically or environmentally.

For coal, the geographical distribution of reserves and resources are very uneven. About $90 \%$ of known geological occurrences, both commercially feasible and infeasible, are concentrated to just six countries (Energywatch Group, 2007). In addition, global production is also focused in a few countries (China alone made up nearly $50 \%$ of world coal output in 2009). In fact, studies have found that the peaking of Chinese coal production might occur relatively soon (Zaipu and Mingyu, 2007; Mohr and Evans, 2009; Lin and Liu, 2010). It is safe to say that the coal projections made in SRES (2000) would put significant expectations on just a few countries, but detailed studies of the most important coal nations do not indicate that such outlooks are reasonable (Höök et al., 2010b).

Coal-to-liquids (CTL) is assumed to be widely applicable and available at costs that are very low, typically below 30 dollars/barrel and even as little as 16 dollar/barrel in some cases (SRES, 2000). Such assumptions seem rather unsound compared to more recent and updated assessments, which end up around 48-75 US\$/barrel (Vallentin, 2009). For example, the world CTL production (32 Mb/d) by 2100 in B2 MESSAGE scenario is higher than the world oil production at the same time. Such an output would require about $10000 \mathrm{Mt}$ of coal annually, which is more than the entire world coal production at present and has been deemed questionable (Höök and Aleklett, 2010). No details on conversion ratios and other important factors are given in SRES (2000), except for the vague technological possibilities. Is it really reasonable to expect CTL to become such a vital part of the global energy system based on little more than optimistic visions about technical possibilities?

It has also been argued that the IPCC seriously underestimates the technical challenges associated with building a new energy system. Pielke et al. (2008) showed that two thirds of all energy efficiency improvements are already built into the scenarios, as they are assuming spontaneous technological change and decarbonisation. In addition, they also demonstrated that the assumed rate of decarbonisation in 35 of the scenarios agreed poorly with reality in 2000-2010, as the rapid growth of the Chinese and Indian economies actually had increased the global carbon and energy intensities. Smil (2008) also pointed out how the scenarios ignored several key facts about global energy and its future, more specifically the Jevons paradox (Jevons, 1866) which has implied that for the last 150 years all energy efficiency improvements have actually been translated into higher energy use.

Finally, Smil (2000) and Bezdek and Wendling (2002) pinpoint that long range energy forecasters have made many inaccurate projections, mostly as overestimations. Many inaccurate forecasts were done in good faith with state-of-the-art models, competent researchers and good funding, showing the difficulty of long-range energy forecasting. To summarize, it appears as if the assumptions made in SRES are outdated and in dire need of re-evaluation and recalibration with recent historical trends. At best, the outlooks are optimistic and at worst they are unreasonable or even unrealistic. 


\section{How limited future fossil energy supply may impact climate}

Fossil fuel depletion constrains the maximum extent of anthropogenic global warming, although this is very complex to handle in a holistic manner. Energy constraints pose a threat to the economy ( $\mathrm{Nel}$ and Cooper, 2009), and similarly changes in human energyrelated behaviours can lead to a broad range of effects on natural ecosystems (Czúcz et al., 2010). However, energy, economy and ecology are seldom seen as three interconnected problems. The lack of widely spread benchmarks for energy constraints in long-term planning has been a problem often forcing analysts to overlook this factor or oversimplify it into exogenous inputs disconnected from the reality of supply. Consequently, only a relatively limited amount of studies have pursued the effects on climate change that limited future production of fossil fuels may have.

Brecha (2008) highlighted that there are both geologic and economic reasons to expect limits in future production and made simplified emission scenarios to explore the consequences. He found that $\mathrm{CO}_{2}$ concentrations would end up somewhere between 500 and $600 \mathrm{ppm}$, corresponding to a $2-3^{\circ} \mathrm{C}$ temperature increase. This is still above the proposed $2^{\circ} \mathrm{C}$ climate ceiling, but far less than the large temperature increases generated by the more extreme scenarios in SRES.

Kharecha and Hansen (2008) used a Bern carbon cycle model and a set of peak oil and gascompatible emission scenarios to explore the implications of peak oil for climate change. It should be noted that they considered coal to be abundant and capable of increasing production up to 2100 in their business-as-usual outlook, resulting in $550 \mathrm{ppm} \mathrm{CO}_{2}$ in the atmosphere. Four other scenarios had more constrained coal production profiles, somewhat more compatible with published peak coal projections (Mohr and Evans, 2009; Höök et al., 2010b; Patzek and Croft, 2010: Rutledge, 2011). The $\mathrm{CO}_{2}$ concentration ended up around 450 ppm for these scenarios and they were found to be largely consistent with current assessments of the cumulative $21^{\text {st }}$ century emissions needed to stabilize atmospheric $\mathrm{CO}_{2}$ at 450 ppm even after factoring in carbon cycle feedbacks.

Another interesting approach was performed by Meinshausen et al. (2009), which used a comprehensive probabilistic analysis. The climatic consequences of burning all proven fossil fuel reserves were explored by time-evolving distributions of 26 SRES and 21 other scenarios. The conclusion was that it was a significant risk to surpass the $2^{\circ} \mathrm{C}$ rise in global temperature due to the cumulative emissions. Victor (2009) raised critique against the proposed measures and highlighted the political problems of a limit to cumulative emissions.

Nel and Cooper (2009) attempted to make a complete treatment of fossil energy, using logistic production models, to better understand its impact on the economy and climate. The emissions were projected to a peak at $11 \mathrm{GtC}$ by 2020 before diminishing to around $6 \mathrm{GtC}$ by 2100. Climate responses were examined with three carbon cycle models, where the Bern model reached atmospheric $\mathrm{CO}_{2}$-levels of $\sim 540$ ppm by 2100 in contrast to the other two models that gave lower atmospheric concentrations. The model with the best fit to historical data peaked at around $430 \mathrm{ppm}$ by 2060 before slowly decreasing. The consequent warming would be limited to about $1^{\circ} \mathrm{C}$ above the 2000 level.

The three studies reached somewhat different results and a lot of this can primarily be attributed to different assumptions about climate sensitivity. Zecca and Chiari (2010a) criticised Nel and Cooper (2009) for underestimating future warming, but Ward and Nel (2011) defended their position. Another paper by Zecca and Chiari (2010b) expanded the 
Climate Change - Research and Technology for Adaptation and Mitigation

discussion of carbon cycle models, but also found that despite methodological differences analysts arrived to the same important conclusion: it is likely that fossil fuel depletion will limit the atmospheric $\mathrm{CO}_{2}$ concentration at levels lower than the ones presented in the IPCC SRES scenarios.

\section{Conclusion}

Peak oil and related limits to future fossil energy extraction has this far received little attention in the climate change debate (Kharecha and Hansen, 2008). It is certainly about time to change this and stop seeing anthropogenic release of $\mathrm{CO}_{2}$ as something detached from future energy supply questions. Energy cannot be seen as a limitless input to economic models and remain disconnected from the physical and logistical realities of supply (Nel and Cooper, 2009).

The current set of scenarios, SRES (2000), is perforated by optimistic expectations on future fossil fuel production that are improbable and some of the scenarios can even be ruled out as clearly unrealistic. The utopian thinking in SRES (Hjerpe and Linnér, 2009), is unsubstantiated in the light of recent developments and there are serious issues with the modelling of future production. Future production is dependent on much more than just geological availability. Rogner (1997), and consequently SRES (2000), places great importance on gas hydrates for a future global energy system. However, Beauchamp (2004) highlighted the fact that huge global estimates of hydrate methane are suspicious at best, and have nothing to do with the likelihood that hydrates will provide energy supply assurance for the future.

Some scenarios would also place unreasonable expectations on just a few countries or regions. Is it reasonable to expect that China would increase their coal production by a factor of 8 over the next 90 years, as implied by the A1C-scenarios? More detailed studies on China has actually placed the likelihood of a peaking in Chinese production relatively soon (Mingyu and Zaipu, 2007; Mohr and Evans, 2009; Lin and Liu, 2010). Energy forecasting on a global perspective sometimes overlooks constraints which occur on a smaller geographical level. Given the uneven geographical distribution of coal (Höök et al., 2010b), it is necessary to revise the emission scenarios to better reflect the reality of global coal production.

Similar issues can be found with expected oil and gas production in several scenarios. The grand production increases seen in optimistic outlooks are not compatible with other studies and appears to have missed the growing body of evidence that supports an imminent peaking of world oil production (UKERC, 2009). Needless to say, many of the assumptions used in SRES (2000) are outdated and in dire need of re-evaluation. Although, they are not outside the realm of extreme possibilities, it is certainly not reasonable as a sound projection compatible with historical trends and recent developments in the field of fossil fuel forecasting. The current stance, where SRES (2000) are much more optimistic about future oil supply than the oil industry and other agencies attempting to forecast future oil supply with high levels of accuracy puts the IPCC in a rather odd or even awkward position. The extreme scenarios with high temperature increases can only be obtained by disregarding supply constraints and projecting continued exponential growth extraction until 2100.

It can be argued that numerous SRES scenarios need to be revised, generally downward, regarding production expectations from fossil fuels. Several scenarios agree poorly with reality over the recent years and some can even be ruled out due to this mismatch. SRES is 
simply underpinned by a paradigm of perpetual growth and technological optimism as well as old and outdated estimates regarding the availability of fossil energy. Although the development of new emission scenarios is underway, there is still a long road left before they are finished and can be implemented.

The golden rule of modelling - "garbage in - garbage out" - should always be held dear. The validity of the climate change projections obtained from climate models can be no more than the soundness of the input that was used to derive those estimates. As anthropogenic climate change is dependent on the choices people make and the development of human society, it is necessary to use forecasts and scenarios for a future global energy system. SRES unnecessarily takes the "optimistic side", effectively disregarding phenomenological models derived from natural science in favour of economic models, instead of providing a sound and more balanced view on resources availability (Höök et al., 2010a).

The extent and timing of peak oil and other impending peaks are not clear, but it is obvious that these events will have a major impact on mankind's future release of $\mathrm{CO}_{2}$ and other GHGs given the importance of fossil fuels as a source of anthropogenic emissions. While continued improvement of the understanding of climate mechanisms is being pursued, it is equally important to refine and evaluate the input that is being used in the climate models. Without proper understanding of energy system developments it is unlikely that future anthropogenic emissions can be realistically projected and neither can the climate change caused by human activities.

There are several feedback and climate mechanisms that can potentially cause severe changes in the climate at lower $\mathrm{CO}_{2}$ concentrations than expected by the IPCC (2007). Consequently, the peaking of fossil fuels should not be seen as something that automatically solves the issue of anthropogenic climate change. Availability and future production paths will, however, put a limit on mankind's ability to emit GHGs and this must be factored into the climate change projections. The current situation, where climate models largely rely on emission scenarios detached from the reality of supply and its inherent problems is problematic. In fact, it may even mislead planners and politicians into making decisions that mitigate one problem but make the other one worse. It is important to understand that the fossil energy problem and the anthropogenic climate change problem are tightly connected and need to be treated as two interwoven challenges necessitating a holistic solution.

\section{Acknowledgments}

I would like to thank Simon Snowden for proofreading. Anders Sivertsson also has my sincerest gratitude for compiling useful material.

\section{References}

Aleklett, K., Campbell, C.J. (2003). The peak and decline of world oil and gas production. Minerals and Energy - Raw Materials Report, Vol.18, No. 1 (January 2003), pp. 5-20, ISSN 1651-2286

Arrhenius, S. (1896). On the influence of carbonic acid in the air upon the temperature of the ground. Philosophical Magazine and Journal of Science, Vol.5, No.41 (April 1896), pp. 237-276, ISSN 1478-6435

Bartlett, A.A. (1993). Arithmetic of growth: methods of calculation. Population and Environment, Vol. 14, No. 4 (March 1993), pp. 359-387, ISSN 0199-0039 
Bartlett, A.A. (1999). Arithmetic of growth: methods of calculation II. Population and Environment, Vol. 20, No. 3 (January 1999), pp. 215-246, ISSN 0199-0039

Bartlett, A.A. (2004). The essential exponential! For the future of our planet, University of Nebraska Press, ISBN 978-0975897300, Lincoln, NE

Beauchamp, B. (2004). Natural gas hydrates: myths, facts and issues. Comptes Rendus Geoscience, Vol. 336, No. 9 (July 2004), pp. 751-765, ISSN 1631-0713

Bentley, R.W., Boyle, G. (2007). Global oil production: forecasts and methodologies, Environment and Planning B: Planning and Design, Vol. 35, No. 4 (July 2007), pp. 609626, ISSN 0265-8135

Bezdek, R.H., Wendling, R.M. (2002). A half century of long-range energy forecasts: errors made, lessons learned, and implications for forecasting. Journal of Fusion Energy, Vol. 21, No. 3-4 (December 2002), pp. 155-172, ISSN 0164-0313

BGR, 2008. Reserves, resources and availability of energy resources 2007, Available from: http://www.bgr.bund.de/

BP, 2010. Statistical review of world energy 2010, Available from: http:/ /www.bp.com

Brecha, R.J. (2008). Emission scenarios in the face of fossil-fuel peaking. Energy Policy, Vol. 36, No. 9 (September 2008), pp. 3492-3504, ISSN 0301-4215

Campbell, C., Laherrère, J. (1998). The end of cheap oil. Scientific American, March 1998, pp. 76-83, ISSN 0036-8733

Castles I., Henderson D. (2003). The IPCC emission scenarios: an economic-statistical critique. Energy E Environment, Vol. 14, No. 2-3 (May 2003), pp. 159-185, ISSN 0958-305X

de Castro, C., Miguel, L.J., Mediavilla, M. (2009). The role of non conventional oil in the attenuation of peak oil. Energy Policy, Vol. 37, No. 5 (May 2009), pp. 1825-1833, ISSN 0301-4215

Coghlan, A. (2003). 'Too little' oil for global warming. New Scientist, 2 August 2003. See also: http://www.newscientist.com/article/dn4216

Curtis, F. (2007). Climate change, peak oil, and globalization: contradictions of natural capital. Review of Radical Political Economics, Vol. 39, No. 3 (September 2007), pp. 385-390, ISSN 0486-6134

Czúsz, B., Gathman, J.P., McPherson, G.R. (2010). The impending peak and decline of petroleum production: an underestimated challenge for conservation of ecological integrity. Conservation Biology, Vol. 24, No. 4 (August 2010), pp. 948-956, ISSN 1523-1739

Dessai, S., O'Brien, K., Hulme, M. (2007). On uncertainty and climate change. Global Environmental Change, Vol. 17, No. 1 (February 2007), pp. 1-3, ISSN 0959-3780

Energywatch Group, 2007. Coal: resources and future production, EWG-paper No. 1/07, Available from: http:/ / www.energywatchgroup.com/

Girod, B., Wiek, A., Mieg, H., Hulme, M. (2009). The evolution of the IPCC's emissions scenarios. Environmental Science \& Policy, Vol. 12, No. 2 (April 2009), pp. 103-118, ISSN 1462-9011

Gray, V. (1998). The IPCC future projections: are they plausible? Climate Research, Vol. 10, No. 2 (August 1998), pp. 155-162, ISSN 1616-1572

Gregory, K., Rogner, H.H. (1998). Energy resources and conversion technologies for the 21st century. Mitigation and Adaptation Strategies for Global Change, Vol. 3, No. 2 (December 1998), pp. 171-229, ISSN 1381-2386 
Green, K.C., Armstrong, J.S., Soon, W. (2009). Validity of climate change forecasting for public policy decision making. International Journal of Forecasting, Vol. 25, No. 4 (October 2009), pp. 826-832, ISSN 0169-2070

Greene, D.L., Hopson, J.L., Li, J. (2006). Have we run out of oil yet? Oil peaking analysis from an optimist's perspective. Energy Policy, Vol. 34, Issue (May 2006), pp. 515-531, ISSN 0301-4215

Groves, D.G., Lempert, R.J. (2007). A new analytic method for finding policy-relevant scenarios. Global Environmental Change, Vol. 17, No. 1 (February 2007), pp. 73-85, ISSN 0959-3780

Grübler, A. (1998). A Review of Global and Regional Sulfur Emission Scenarios. Mitigation and Adaptation Strategies for Global Change, Vol.3, No. 2-4 (December 1998), pp. 383418, ISSN 1381-2386

Grübler, A., Nakićenović, N. (2001). Identifying dangers in an uncertain climate. Nature, Vol. 412, No. 6842 (July 2001), pp. 15, ISSN 0028-0836

Hjerpe, M, Linnér, B.O. (2008). Utopian and dystopian thought in climate change science and policy. Futures, Vol. 41, No. 4 (May 2009), pp. 234-245, ISSN 0016-3287

Hubbert, M.K. (1956). Nuclear energy and the fossil fuels. Publication No. 95, 40 pp. Shell Development Company, Houston, Texas.

Höök, M., Hirsch, R., Aleklett, K. (2009). Giant oil field decline rates and their influence on world oil production. Energy Policy, Vol. 37, No. 6 (June 2009), pp. 2262-2272, ISSN 0301-4215

Höök, M., Aleklett, K. (2010). A review on coal to liquid fuels and its coal consumption. International Journal of Energy Research, Vol. 34, No. 10 (October 2010), pp. 848-864, ISSN 1099-114X

Höök, M., Sivertsson, A., Aleklett, K. (2010a). Validity of the fossil fuel production outlooks in the IPCC Emission Scenarios. Natural Resources Research, Vol. 19, No. 2 (June 2010), pp. 63-81, ISSN 1520-7439

Höök, M., Zittel, W., Schindler, J., Aleklett, K. (2010b). Global coal production outlooks based on a logistic model. Fuel, Vol. 89, No. 11 (November 2010), pp. 3546-3558, ISSN 0016-2361

Höök, M., Bardi., U., Feng, L., Pang, X. (2010c). Development of oil formation theories and their importance for peak oil. Marine and Petroleum Geology, Vol.27, No. 9 (October 2010), pp. 1995-2004, ISSN 0264-8172

IEA, (2010). Key World Energy Statistics 2010. Available from http:/ / www.iea.org

IPCC, (1990). First Assessment Report, Available from http:/ / www.ipcc.ch/

IPCC, (1995). Second Assessment Report, Available from http://www.ipcc.ch/

IPCC, (2001). Third Assessment Report, Available from http://www.ipcc.ch/

IPCC (2007). Fourth Assessment Report, Available from http:/ / www.ipcc.ch/

Jevons, W.S. (1856). The coal question: an inquiry concerning the progress of the nation, and the probable exhaustion of our coal-mines, Augustus M Kelley Pubs, ISBN 978-0678001073, London, England

Jones, R.N. (2001). An environmental risk assessment/management framework for climate change impact assessments. Natural Hazards, Vol. 23, No. 2-3 (March 2001), pp. 197230, ISSN 0921-030X 
Kharecha, P.A., Hansen, J.E. (2008). Implications of "peak oil" for atmospheric $\mathrm{CO}_{2}$ and climate. Global Biogeochemical Cycles, Vol. 22, No. 3 (August 2008), GB3012, ISSN 0886-6236

Laherrere, J. (2001). Estimates of oil reserves. Paper presented at the EMF/IEA/IEW meeting, International Institute for Applied Systems Analysis (IIASA), Laxenburg, Austria - June 19, 2001.

Laherrere, J. (2002). Forecasting future production from past discovery. International Journal of Global Energy Issues, Vol. 18, No. 2-4 (April 2002), pp. 218-238, ISSN 1741-5128

Lin B.Q., Liu, J.H. (2010). Estimating coal production peak and trends of coal imports in China. Energy Policy. Vol. 38, No. 1 (January 2010), pp. 512-519, ISSN 0301-4215

Lior, N. (2009). Energy resources and use: The present situation and possible paths to the future. Energy, Vol. 33, No. 6 (June 2008), pp. 842-857, ISSN 0360-5442

Lemos, C.M., Rood, R.B. (2010). Climate projections and their impact on policy and practice. Wiley Interdisciplinary Reviews: Climate Change, Vol. 1, No. 5 (September 2010), pp. 670-682, ISSN 1757-7799

Malthus, T. (1798). An essay on the principle of population, Penguin Classics, ISBN 9780140432060, London, England, 304 p.

McCartney, G., Hanlon, P., Romanes, F. (2008). Climate change and rising energy costs will change everything: A new mindset and action plan for 21st Century public health. Public Health, Vol. 122, No. 7 (July 2008), pp. 658-663, ISSN 0033-3506

McKibbin W.J., Pearce, D., Stegman, A. (2007). Long term projections of carbon emissions. International Journal of Forecasting, Vol. 23, No. 4 (October-December 2007), pp. 637653, ISSN 0169-2070

Meadows, D.H., Meadows, D.L., Randers, J., Behrens, W. (1972). The limits to growth, Universe Books, ISBN 978-0451136954, New York, USA

Meinshausen, M., Meinshausen, N., Hare, W., Raper, S.C.B., Friler, K. Knutti, R., Frame, D.J., Allen, M.,R. (2009). Greenhouse-gas emission targets for limiting global warming to $2^{\circ} \mathrm{C}$. Nature, Vol. 458, No. 7242 (April 2009), pp. 1158-1162, ISSN 0028-0836

Milkov, A.V. (2004). Global estimates of hydrate-bound gas in marine sediments: how much is really out there? Earth-Science Reviews, Vol. 66, No. 3-4 (August 2004), pp. 183197, ISSN 0012-8252

Mohr, S.H, Evans, G.M. (2009). Forecasting coal production until 2100. Fuel, Vol. 88, No. 11 (November 2009), pp. 2059-2067, ISSN 0016-2361

Moriatry, P., Honnery, D. (2009). What energy levels can the Earth sustain? Energy Policy, Vol.37, No. 7 (July 2009), pp. 2469-2474, ISSN 0301-4215

Nakićenović, N., Victor, N., Morita, T. (1998). Emissions Scenarios Database and Review of Scenarios. Mitigation and Adaptation Strategies for Global Change, Vol. 3, No. 2 (December 1998), pp. 95-131, ISSN: 1381-2386

Nel, W.P., Cooper, C.J. (2009). Implications of fossil fuel constraints on economic growth and global warming. Energy Policy, Vol. 37, No. 1(January 2009), pp. 166-180, ISSN 0301-4215

Patzek, T.W., Croft, G.D. (2010). A global coal production forecast with multi-Hubbert cycle analysis. Energy, Vol. 35, No. 8 (August 2010), pp. 3109-3122, ISSN 0360-5442

Peterson, T.C., Connolley, W.M., Fleck, J. (2008). The myth of the 1970s global cooling scientific consensus. Bulletin of the American Meterological Society, Vol. 89 No. 9 (September 2008), pp. 1325-1357, ISSN 1520-0477 
Pielke, R., Wigley, T., Green, C. (2008). Dangerous assumptions. Nature, Vol. 454, No. 7187 (April 2008), pp. 531-532, ISSN 0028-0836

Rogner, H.H. (1997). An assessment of world hydrocarbon resources. Annual Review of Energy and the Environment, Vol. 22, No. 1 (November 1997), pp. 217-262, ISSN 1056-3466

Rutledge, D. (2007). Hubbert's Peak, the Coal Question, and Climate Change, presentation at the ASPO-USA World Oil Conference, 17-20 October 2007, Houston, Texas, Available from: http:/ / rutledge.caltech.edu/

Rutledge, D. (2011). Estimating long-term world coal production with logit and probit transforms. International Journal of Coal Geology, Vol. 85, No. 1 (January 2011), pp. 23-33, ISSN 0166-5162

Schenk, N.J., Lensink, S.M. (2007). Communicating uncertainty in the IPCC's greenhouse gas emissions scenarios. Climatic Change, Vol. 82 No. 1-2 (June 2007), pp. 293-308, ISSN 0165-0009

Schneider, S.H. (2001). What is "dangerous" climate change? Nature, Vol. 411, No. 6833 (May 2001), pp. 17-19, ISSN 0028-0836

Schneider, S.H. (2002). Can we estimate the likelihood of climatic changes at 2100? Climatic Change, Vol. 52, No. 4 (March 2002), pp. 441-451, ISSN 0165-0009

Sivertsson, A. (2004). Study of world oil resources with a comparison to the IPCC emissions scenarios. Master thesis from Uppsala University. Available from http://www.tsl.uu.se/uhdsg/Publications/Sivertsson_Thesis.pdf

Smil, V. (2000). Perils of long-range energy forecasting: reflections on looking far ahead. Technological Forecasting and Social Change, Vol. 65, No. 3 (November 2000), pp. 251-264, ISSN 0040-1625

Smil, V. (2008). Long-range energy forecasts are no more than fairy tales. Nature, Vol. 453, No. 7187 (May 2008), pp. 531-532, ISSN 0028-0836

Sorrell, S., Miller, J., Bentley, R., Speirs, J. (2010). Oil futures: A comparison of global supply forecasts. Energy Policy, Vol. 38, No. 9 (September 2010), pp. 4990-5003, ISSN 03014215

SRES, 2000. Special Report on Emissions Scenarios. Report prepared for the Third Assessment Report. November 2000. Available from: http:/ / www.ipcc.ch/

Tao, Z. Li. (2007). What is the limit of Chinese coal supplies -- A STELLA model of Hubbert Peak. Energy Policy, Vol. 35, No. 6 (June 2007), pp. 3145-3154, ISSN 0301-4215

Tol, R.S.J. (2006). Exchange rates and climate change: an application of fund. Climatic Change, Vol. 75, No. 1-2 (March 2006), pp. 59-80, ISSN 0165-0009

Turner, G.M. (2008). A comparison of The Limits to Growth with 30 years of reality. Global Environmental Change, Vol. 18, No. 3 (August 2008), pp. 397-411, ISSN 0959-3780

van Ruijven, B., Urban, F., Benders, R.M.J., Moll, H.C., van der Sluijs, J.P., de Vries, B., van Vuuren, D.P. (2008). Modeling energy and development: an evaluation of models and concepts. World Development, Vol. 36, No. 12 (December 2008), pp. 2801-2821, ISSN 0305-750X

Valero, A., Valero, A. (2011). A prediction of the exergy loss of the world's mineral reserves in the 21st century. Energy, Vol. 36, No. 4 (April 2011), pp. 1848-1854, ISSN 03605442 
Vallentin, D. (2008). Policy drivers and barriers for coal-to-liquids (CTL) technologies in the United States. Energy Policy, Vol. 36, No. 8 (August 2008), pp. 3198-3211, ISSN 0301-4215

Verhulst, P.F. (1838). Notice sur la loi que la population suit dans son accroissement. Correspondence Mathematique et Physique, Vol. 10, pp. 113-121

Victor, D.G. (2009). Global warming: Why the $2^{\circ} \mathrm{C}$ goal is a political delusion. Nature, Vol. 459, No. 7249 (June 2009), pp. 909, ISSN 0028-0836

van Vuuren, D.P., O'Neill, B.C., 2006. The Consistency of IPCC's SRES Scenarios to 19902000 Trends and Recent Projections. Climatic Change, Vol. 75, No. 1-2 (March 2006), pp. 9-46, ISSN 0165-0009

van Vuuren, D.P., de Vries, B., Beusen, A., Heuberger, P.S.C. (2008). Conditional probabilistic estimates of 21st century greenhouse gas emissions based on the storylines of the IPCC-SRES scenarios. Global Environmental Change, Vol. 8, No. 4 (October 2008), pp. 635-654, ISSN 0959-3780

Walsh, K.J.E., Betts, H., Church, J., Pittock, A.B., McInnes, K.L., Jackett, D.R., McDougall, T.J. (2004). Using Sea Level Rise Projections for Urban Planning in Australia. Journal of Coastal Research, Vol. 20, No. 2 (March 2004), pp. 586-598, ISSN 0749-0208

Ward, J.D., Nel, W.P. (2011). Comment on Fossil-fuel constraints on global warming by A. Zecca and L. Chiari. Energy Policy, article in press, ISSN 0301-4215

Webster, M.D., Forest, C., Reilly, J.M., Babiker, M., Kickligher, D., Mayer, M., Prinn, R., Sarofim, M.C., Sokolov, A., Stone, P., Wang, C. (2003). Uncertainty analysis of climate change and policy response. Climatic Change, Vol. 61, No. 3 (December 2003), pp. 295-320, ISSN 0165-0009

World Wind Energy Association (2009). World wind energy report 2009. Available from http:/ / www.wwindea.org/

UKERC, (2009). Global oil depletion: an assessment of the evidence for a near-term peak in global oil production, UK Energy Research Centre, London, Available from: http://www.ukerc.ac.uk/support/Global\%20Oil\%20Depletion

Zecca, A., Chiari, L. (2010a). Fossil-fuel constraints on global warming. Energy Policy, Vol. 38, No. 1 (January 2010), pp. 1-3, ISSN 0301-4215

Zecca, A., Chiari, L. (2010b). Observational constraints of the past $\mathrm{CO}_{2}$ concentration on the results of carbon cycle models. Energy Policy, article in press, ISSN 0301-4215 


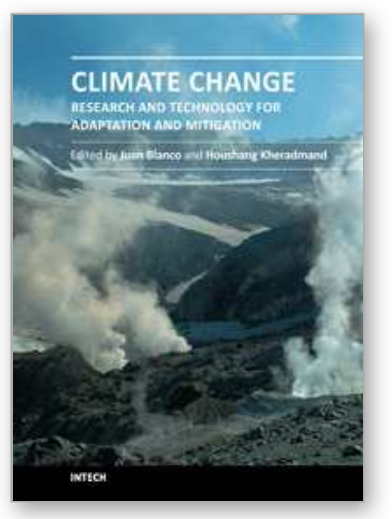

\section{Climate Change - Research and Technology for Adaptation and Mitigation}

Edited by Dr Juan Blanco

ISBN 978-953-307-621-8

Hard cover, 488 pages

Publisher InTech

Published online 06, September, 2011

Published in print edition September, 2011

This book provides an interdisciplinary view of how to prepare the ecological and socio-economic systems to the reality of climate change. Scientifically sound tools are needed to predict its effects on regional, rather than global, scales, as it is the level at which socio-economic plans are designed and natural ecosystem reacts. The first section of this book describes a series of methods and models to downscale the global predictions of climate change, estimate its effects on biophysical systems and monitor the changes as they occur. To reduce the magnitude of these changes, new ways of economic activity must be implemented. The second section of this book explores different options to reduce greenhouse emissions from activities such as forestry, industry and urban development. However, it is becoming increasingly clear that climate change can be minimized, but not avoided, and therefore the socio-economic systems around the world will have to adapt to the new conditions to reduce the adverse impacts to the minimum. The last section of this book explores some options for adaptation.

\section{How to reference}

In order to correctly reference this scholarly work, feel free to copy and paste the following:

Mikael Höök (2011). Fuelling Future Emissions - Examining Fossil Fuel Production Outlooks Used in Climate Models, Climate Change - Research and Technology for Adaptation and Mitigation, Dr Juan Blanco (Ed.), ISBN: 978-953-307-621-8, InTech, Available from: http://www.intechopen.com/books/climate-changeresearch-and-technology-for-adaptation-and-mitigation/fuelling-future-emissions-examining-fossil-fuelproduction-outlooks-used-in-climate-models

\section{INTECH}

open science | open minds

\section{InTech Europe}

University Campus STeP Ri

Slavka Krautzeka 83/A

51000 Rijeka, Croatia

Phone: +385 (51) 770447

Fax: +385 (51) 686166

www.intechopen.com

\section{InTech China}

Unit 405, Office Block, Hotel Equatorial Shanghai

No.65, Yan An Road (West), Shanghai, 200040, China 中国上海市延安西路65号上海国际贵都大饭店办公楼 405 单元

Phone: +86-21-62489820

Fax: +86-21-62489821 
(C) 2011 The Author(s). Licensee IntechOpen. This chapter is distributed under the terms of the Creative Commons Attribution-NonCommercialShareAlike-3.0 License, which permits use, distribution and reproduction for non-commercial purposes, provided the original is properly cited and derivative works building on this content are distributed under the same license. 